\title{
A Combined Numerical and Experimental Study of Heat Transfer in a Roughened Square Channel with $45^{\circ}$ Ribs
}

\author{
M. E. Taslim \\ Mechanical and Industrial Engineering Department, Northeastern University, Boston, MA 02115, USA \\ Email:m.taslim@neu.edu \\ H. Liu \\ Mechanical and Industrial Engineering Department, Northeastern University, Boston, MA 02115, USA \\ Email: haidongl@coe.neu.edu
}

Received 10 October 2003

\begin{abstract}
Experimental investigations have shown that the enhancement in heat transfer coefficients for air flow in a channel roughened with low blockage $\left(e / D_{h}<0.1\right)$ angled ribs is on the average higher than that roughened with $90^{\circ}$ ribs of the same geometry. Secondary flows generated by the angled ribs are believed to be responsible for these higher heat transfer coefficients. These secondary flows also create a spanwise variation in the heat transfer coefficient on the roughened wall with high levels of the heat transfer coefficient at one end of the rib and low levels at the other end. In an effort to investigate the thermal behavior of the angled ribs at elevated Reynolds numbers, a combined numerical and experimental study was conducted. In the numerical part, a square channel roughened with $45^{\circ}$ ribs of four blockage ratios $\left(e / D_{h}\right)$ of $0.10,0.15,0.20$, and 0.25 , each for a fixed pitch-to-height ratio $(P / e)$ of 10 , was modeled. Sharp as well as round-corner ribs $(r / e=0$ and 0.25$)$ in a staggered arrangement were studied. The numerical models contained the smooth entry and exit regions to simulate exactly the tested geometries. A pressure-correctionbased, multiblock, multigrid, unstructured/adaptive commercial software was used in this investigation. Standard high Reynolds number $k-\varepsilon$ turbulence model in conjunction with the generalized wall function for most parts was used for turbulence closure. The applied thermal boundary conditions to the CFD models matched the test boundary conditions. In the experimental part, a selected number of these geometries were built and tested for heat transfer coefficients at elevated Reynolds numbers up to 150000 , using a liquid crystal technique. Comparisons between the test and numerically evaluated results showed reasonable agreements between the two for most cases. Test results showed that (a) $45^{\circ}$ angled ribs with high blockage ratios $(>0.2)$ at elevated Reynolds numbers do not exhibit a good thermal performance, that is, beyond this blockage ratio, the heat transfer coefficient decreases with the rib blockage and (b) CFD could be considered as a viable tool for the prediction of heat transfer coefficients in a rib-roughened test section.
\end{abstract}

Keywords and phrases: turbine airfoil cooling, rib roughness.

\section{INTRODUCTION}

Heat transfer coefficient in a channel flow can be increased by roughening the walls of the channel. One such method, used over the past thirty years in internal cooling passages, is to mount rib-shape roughnesses on the channel walls. These ribs, also called turbulators, increase the level of mixing of the cooler core air with the warmer air close to the channel wall, thereby, enhancing the cooling capability of the passage. Geometric parameters such as channel aspect ratio (AR), rib height-to-passage hydraulic diameter or blockage

This is an open access article distributed under the Creative Commons Attribution License, which permits unrestricted use, distribution, and reproduction in any medium, provided the original work is properly cited. ratio $\left(e / D_{h}\right)$, rib angle of attack $(\alpha)$, the manner in which the ribs are positioned relative to one another (in-line, staggered, crisscross, etc.), rib pitch-to-height ratio $(P / e)$, and the rib shape (round versus sharp corners, fillets, rib aspect ratio $\left(\mathrm{AR}_{t}\right)$, and skewness towards the flow direction) have pronounced effects on both local and the overall heat transfer coefficients. Some of these effects were studied by different investigators such as Burggraf [1], Chandra et al. [2, 3], Han et al. [4, 5, 6], Metzger et al. [7], Taslim et al. [8, 9], and Webb et al. [10]. Among those geometries close to the present investigation are studied in the papers by Lau et al. [11] and Han et al. [12]. These last two references deal with heat transfer characteristics of turbulent flow in a square channel with angled discrete ribs. Heat transfer performance of $30^{\circ}, 45^{\circ}, 60^{\circ}$, and $90^{\circ}$ discrete, parallel, and crossed ribs was 


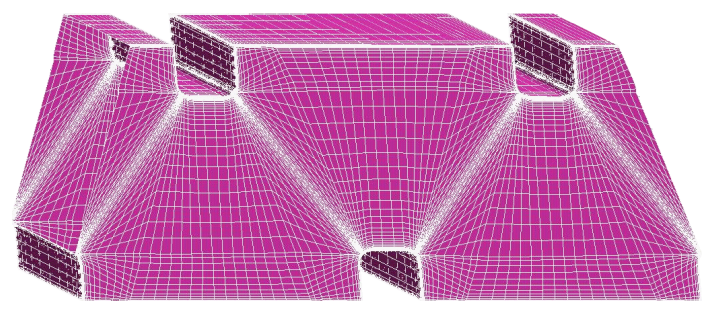

Figure 1: A representative mesh arrangement for a ribbed section of the channel.

investigated. The second investigation studied the augmentation of heat transfer in square channels roughened with parallel, crossed, and V-shaped ribs. While their rib pitchto-height ratio of 10 was identical to that in this study, the rib height-to-channel hydraulic diameter was 0.0625 in both investigations which is below the range tested in the present investigation $(0.083-0.167)$. However, results of the smallest rib tested in this investigation are compared with those tested in the two above-mentioned references.

\section{COMPUTATIONAL MODELS}

The computational models were constructed for a $45^{\circ}$ ribroughened channel with eight ribs on each side in a staggered arrangement. The domain included the entry and exit regions exactly simulating the test setup. Numerical models were meshed and run for ribs with all sharp corners as well as ribs with round-top corners of $r / e=0.25$. Rib blockage ratio $\left(e / D_{h}\right)$ varied as $0.10,0.15,0.20$, and 0.25 while the rib pitch-to-height ratios $(P / e)$ remained constant at 10. Figure 1 shows a representative meshed domain for the rib geometry of $e / D_{h}=0.25$ which includes the air flow region between three ribs on the bottom wall and two ribs on the top wall. This arrangement continues on both sides to cover the entire channel length of $152.4 \mathrm{~cm}$ with a total of sixteen ribs. The computational domain size for the other rib geometries was the same. The CFD analysis was performed using Fluent/UNS solver by Fluent, Inc., a pressure-correction based, multiblock, multigrid, unstructured/adaptive solver. Standard high Reynolds number $k-\varepsilon$ turbulence model in conjunction with the generalized wall function was used for turbulence closure. Other available turbulence models in this commercial code, short of a two-layer model which required a change in mesh arrangement for each geometry and was beyond the scope of this investigation, were also tested and did not produce results significantly different from those of the $k-\varepsilon$ model. Mesh independence was achieved at about 700000 cells for a typical model. Cells in all models were entirely hexagonal, a preferred choice for CFD analyses, and were varied in size bigeometrically from the boundaries to the center of the computational domain in order to have a finer mesh close to the boundaries. Figure 2 shows the details of the mesh distribution on the surface of the domain. It is seen that there are regions of high mesh concentration close to the rib surfaces in order to capture the viscous effects in the recirculating zones.

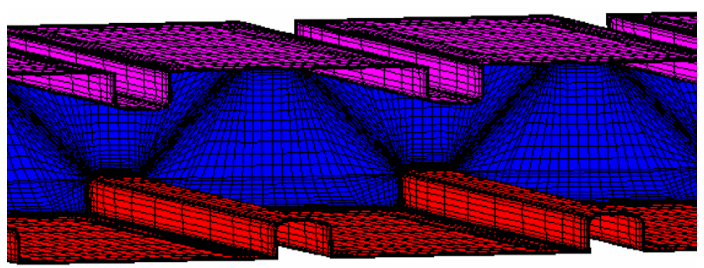

FIGURE 2: Details of the mesh arrangement on the channel surface.

\section{TEST SECTIONS}

Figure 3 shows schematically the layout of the test apparatus, channel cross-sectional area, and details of the rib geometry for a typical test setup. The steady-state liquid crystal technique was employed to measure the heat transfer coefficients between a pair of ribs in these test sections. In this technique, the most temperature-sensitive color displayed by the liquid crystals is chosen as the reference color corresponding to a known temperature. By sensitive variation of the Ohmic power to a constant heat flux thin-foil heater beneath the liquid crystals, the reference color is moved from one location to another such that the entire area between two ribs is eventually covered with the reference color at constant flow conditions. This process results in a series of photographs each corresponding to a certain location of the reference color. The area covered by the reference color for each photograph is then digitized and an area-weighted average heat transfer coefficient is calculated along with the iso- $\mathrm{Nu}$ contours. The test section, with a length of $152.4 \mathrm{~cm}$, had a $5.08 \mathrm{~cm} \times 5.08 \mathrm{~cm}$ cross-sectional area. Three walls of this channel were made of $1.27-\mathrm{cm}$-thick clear acrylic plastic. The fourth wall, on which the heaters and liquid crystal sheets were attached and all measurements were taken, was made of a 10.16-cm-thick machinable polyurethane slab. Ribs were machined to the size from acrylic plastic stocks and were mounted on two opposite walls in a staggered arrangement at a $45^{\circ}$ angle with the channel flow. The entrance region of all test sections was left smooth to produce well-established hydrodynamic and thermal boundary layers. Heat transfer measurements were performed for an area between a pair of ribs in the middle of the roughened zone corresponding to $X / D_{h}=15$. Five $5.08 \times 27.94 \mathrm{~cm}$ custom-made etchedfoil heaters with a thickness of $0.15 \mathrm{~mm}$ were placed on the polyurethane wall where measurements were taken using a special double-stick $0.05-\mathrm{mm}$-thick tape with minimal temperature deformation characteristics. The heaters covered the entire test section length including the smooth entry length. However, they did not extend over the actual rib surface nor on the acrylic plastic sidewalls. Thus the reported heat transfer coefficients are the averages over the wall surface area between a pair of ribs. The heat transfer coefficient on the rib surfaces are reported by investigators such as Metzger et al. [13], Korotky and Taslim $[14,15]$, and Taslim and Lengkong $[16,17]$. Encapsulated liquid crystals sandwiched between a mylar sheet and a black-paint coat, collectively having 


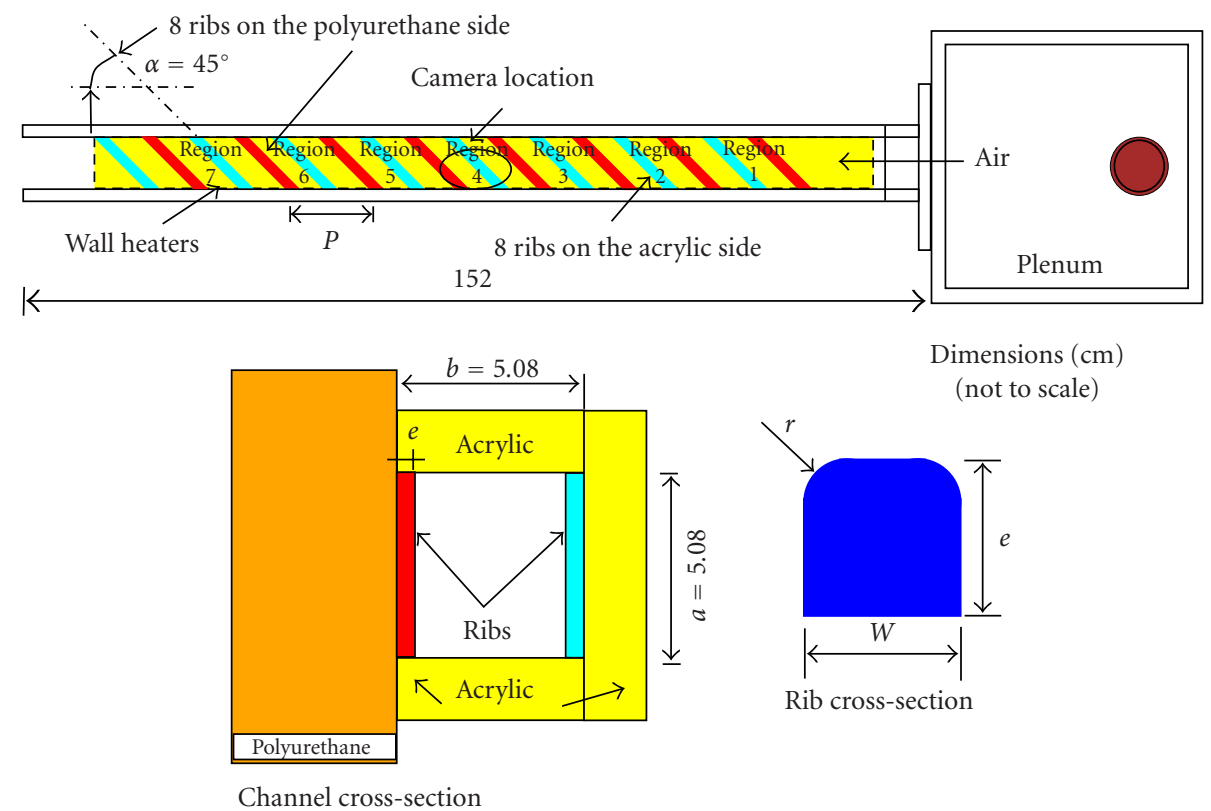

Figure 3: Schematics of a typical test section and ribs.

a thickness of $0.127 \mathrm{~mm}$, were then placed on the heaters. The test sections were covered on all sides by 5 - $\mathrm{cm}$-thick styrofoam sheets to minimize heat losses to the environment, except for a small window on the opposite wall at the location where photographs of the liquid crystals were taken. The radiational heat loss from the heated wall to the unheated walls as well as losses to ambient air were taken into consideration when heat transfer coefficients were calculated. A $35 \mathrm{~mm}$ programmable camera, in conjunction with proper filters and background lighting to simulate daylight conditions, was used to take photographs of isochrome patterns formed on the liquid crystal sheet. Surface heat flux in the test section was generated by the heaters through a customdesigned power supply unit. Each heater was individually controlled by a variable transformer. Before testing, the liquid crystal sheets were calibrated in a water bath and the reference color was measured. A contact micromanometer with an accuracy of $0.025 \mathrm{~mm}$ of water column measured the pressure differential across the rib-roughened channel. A critical venturi-meter, with choked flow for all cases tested, measured the total mass flow rate entering the test section. Experimental uncertainties, following the method of Kline and McClintock [18], were estimated to be $6 \%$ for the heat transfer coefficient.

\section{RESULTS AND DISCUSSION}

Figure 4 shows a comparison between the numerical and experimental results for all rib blockage ratios and a typical pitch-to-height ratio of $P / e=10$. For consistency, the numerical results of region 4 (see Figure 3), corresponding to the location of the camera where data were collected, are compared with the test results. While a maximum difference of about $20 \%$ is observed for the ribs with the highest

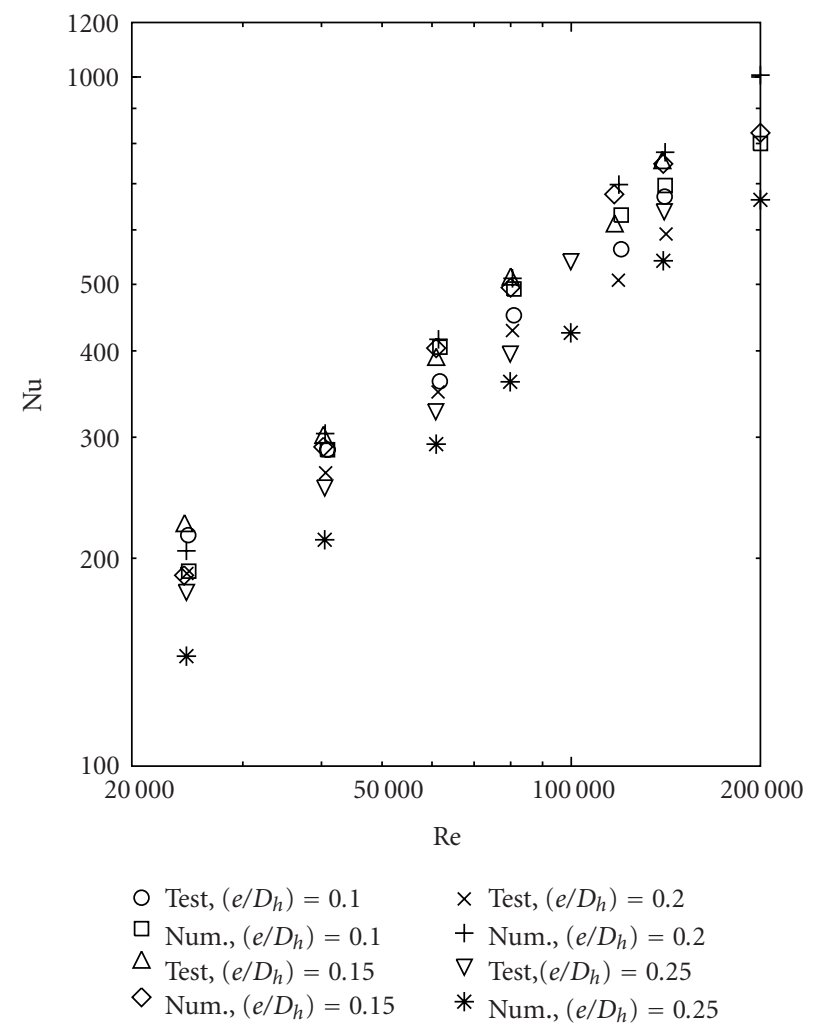

Figure 4: Comparison between the numerical and test results $(P / e=10)$.

blockage ratio at the lowest Reynolds number, the differences are reduced to about $2 \%$ for the intermediate blockage ratios of 0.15 and 0.2 especially at the higher end of the Reynolds 


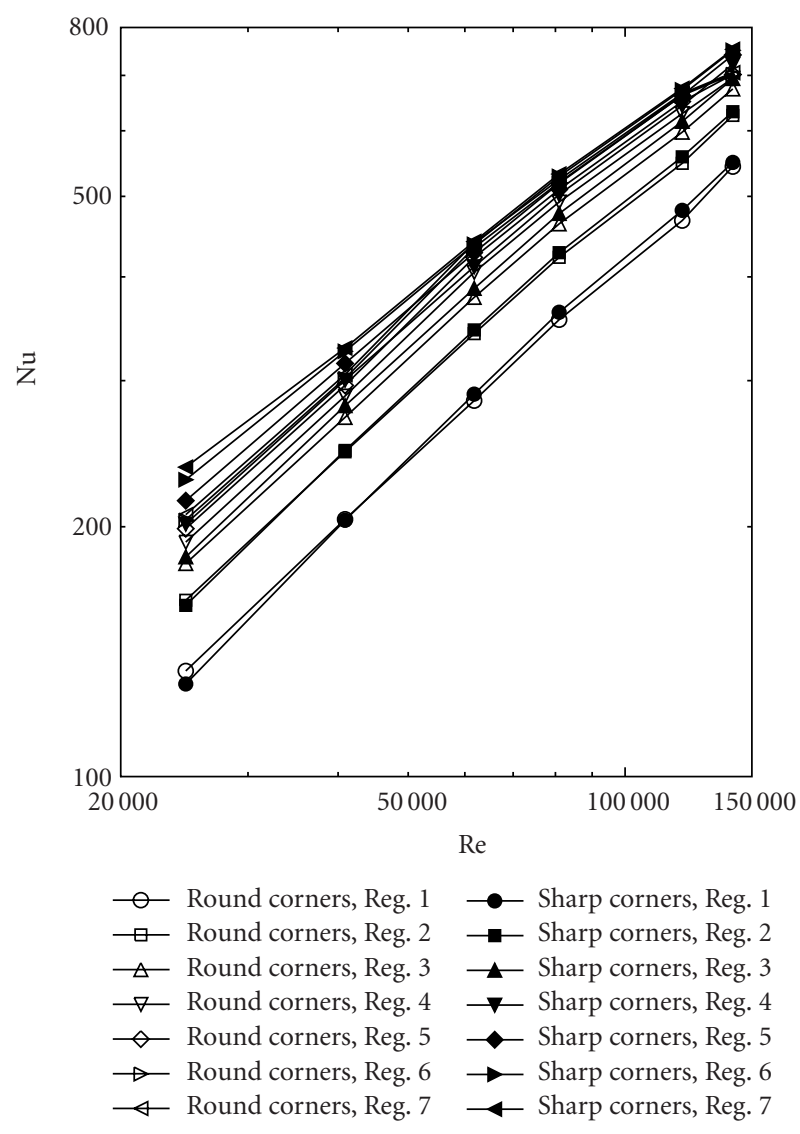

FIGURE 5: Comparison between the numerical results for sharp- and round-corner ribs with $10 \%$ blockage ratio $\left(e / D_{h}=0.1, P / e=10\right)$.

number range. The agreement between the numerical and test results for the lower blockage ribs is very encouraging given that a combination of moderate mesh distribution and traditional $k-\varepsilon$ turbulence model was used with a reasonable convergence time on a typical PC. The high blockage ribs, especially when they are angled with respect to the flow direction as was the case in this investigation, create such a complex flow field that capturing all effects may require much more mesh concentration with possibly a two-layer model for turbulence. Nevertheless, CFD codes are becoming a viable tool in predicting the convective heat transfer coefficients in parametric studies during the early stage of the cooling system designs. It should be noted that the highest tested Reynolds number was around 140000 , while the numerical cases were run for up to 200000 and, as it can be seen, the numerical Nusselt numbers continued to increase with the same trend. Figure 4 also indicates that, unlike the case of $90^{\circ}$ ribs, higher blockage ratio ribs at a $45^{\circ}$ angle with the axial flow direction do not necessarily produce a higher heat transfer coefficients than the smaller ribs. It is seen that as the blockage ration increases from 0.1 to 0.15 , the heat transfer coefficient will increase accordingly. However, as the blockage ratio further increases, the heat transfer coefficient starts to decrease. Both test and numerical results confirm this behavior. A possible explanation is that for

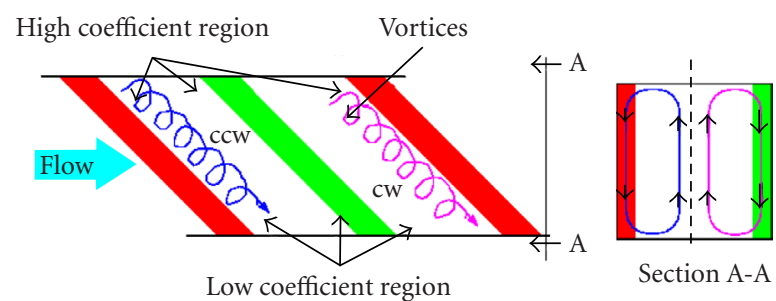

FIGURE 6: Cell formation for angled ribs.

bigger ribs, the air after tripping over these big ribs will not reattach to the channel surface between the ribs as effectively as it would when the ribs are at a $90^{\circ}$ angle with the flow direction; thus a fairly big recirculating zone forms behind the large ribs and the cooling air will not interact thermally with the channel surface. In the extreme case, if the larger angled ribs are positioned too close to each other, the core air may jump from the top of one rib to another and entirely miss the area in between the ribs. In such cases, a re-circulation air zone similar to a cavity flow will fill the space between the ribs and the heat transfer coefficient will reduce remarkably.

Figure 5 shows the numerical results for the smallest rib geometry $\left(e / D_{h}=0.1\right)$ along the channel from region 1 through region 7 for sharp-corner ribs $(r / e=0)$ as well as rib with round corners $(r / e=0.25)$. Solid symbols represent the sharp-corner rib results and hollow symbols show the results of round-corner ribs. Several observations are made. Region 1 shows a lower heat transfer coefficient because this region (see Figure 3) does not benefit from the secondary flows created by either any upstream ribs or ribs on the opposite wall. There is a remarkable increase in heat transfer coefficient along the flow direction from region 1 to region 4 . This increase, however, slows down asymptotically from there on. Secondary flows caused by the presence of angled ribs swirl along the ribs and create a pair of counter-rotating cells (Fan et al. [19] and Metzger et al. [20]) as depicted in Figure 6. These vortices have an additive effect along the channel and, as a result, Nusselt number increases along the channel from region 1 to region 7 . It is also noted that, similar to the case of $90^{\circ}$ ribs that are investigated by these and other investigators, sharp-corner ribs produce higher heat transfer coefficients. Vortices shed from the sharp corners enhance the mixing of the near-wall warm air with the cooler core air thus increasing the heat transfer coefficients compared to those of round-corner ribs which are streamlined. As the blockage ratio increases, some of these trends change as we will discuss shortly. Figure 7 represents the same results for a larger rib $\left(e / D_{h}=0.15\right)$. A similar behavior to a lesser degree is observed for most cases except that the Nusselt number variation in the flow direction is only pronounced from region 1 to 2. For other regions, the Nusselt number shows a slight increase first and a slight decrease from region 4 to region 7. It is speculated that stronger secondary flows created by these larger ribs establish the flow domain faster than the previous case of smaller ribs, thus only a slight variation 


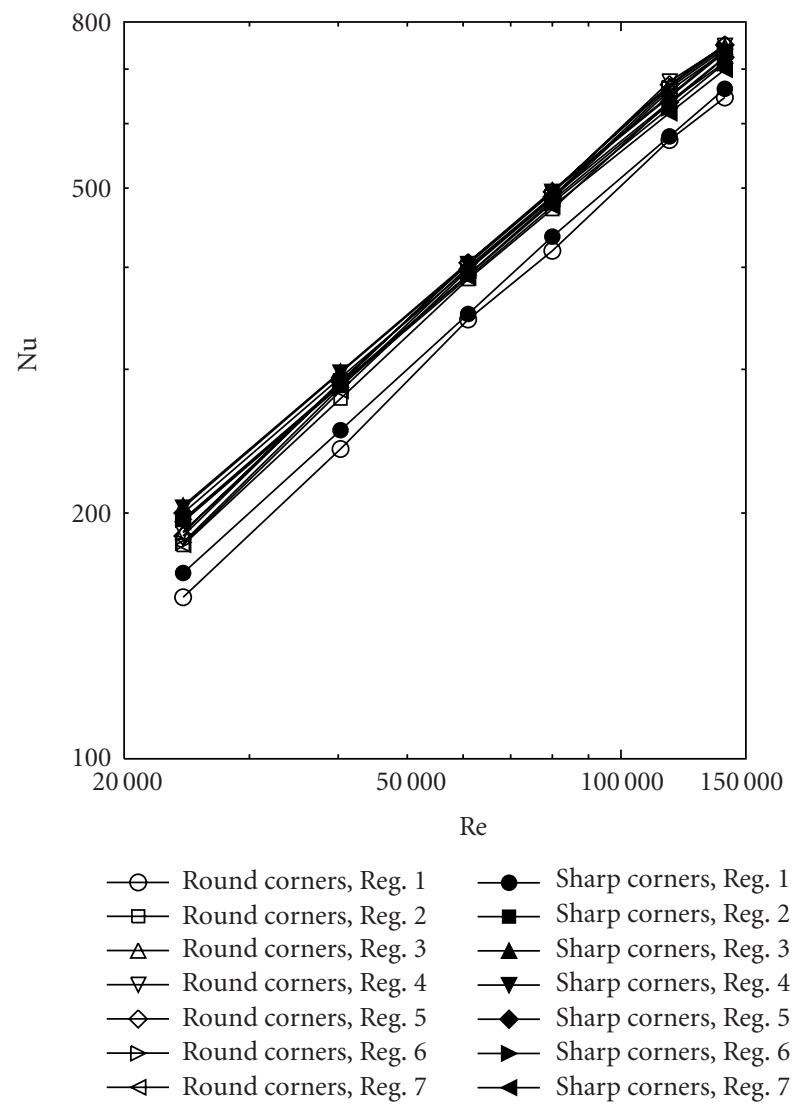

Figure 7: Comparison between the numerical results for sharp- and round-corner ribs with $15 \%$ blockage ratio $\left(e / D_{h}=0.15, P / e=10\right)$.

in Nusselt number is seen. Same observations are made for the next rib blockage ratio of 0.2 , the results of which are shown in Figure 8. However, for a yet larger rib geometry $\left(e / D_{h}=0.25\right)$, the results of which are shown in Figure 9, all trends that were observed to the smaller ribs have changed. First, sharp-corner ribs produced lower heat transfer coefficients than round-corner ribs. For these large ribs with sharp corners, air, after separating from the rib top surface, will not reattach as effectively as it would for the case of round-corner ribs. At the same time, although stronger vortices may shed from the sharp edges, they are dissipated to the core flow and do not get a chance to scrub against the surface area between the ribs. The end result is a lower heat transfer coefficient for the sharp-corner ribs. It is also seen that, for these large ribs, the Nusselt number decreases along the test section. It is speculated that the secondary flows and shed vortices from the rib corners additively reduce the flow reattachment strength in the flow direction thus causing a continuous reduction in the heat transfer coefficient along the flow direction.

Figures 10 and 11 show the isotherms and iso-Nu contours, extracted from the numerical solutions, for a typical region between a pair of ribs in the middle of the channel. It can be seen that the bottom-right region corresponds to the lowest temperature region and the highest Nusselt

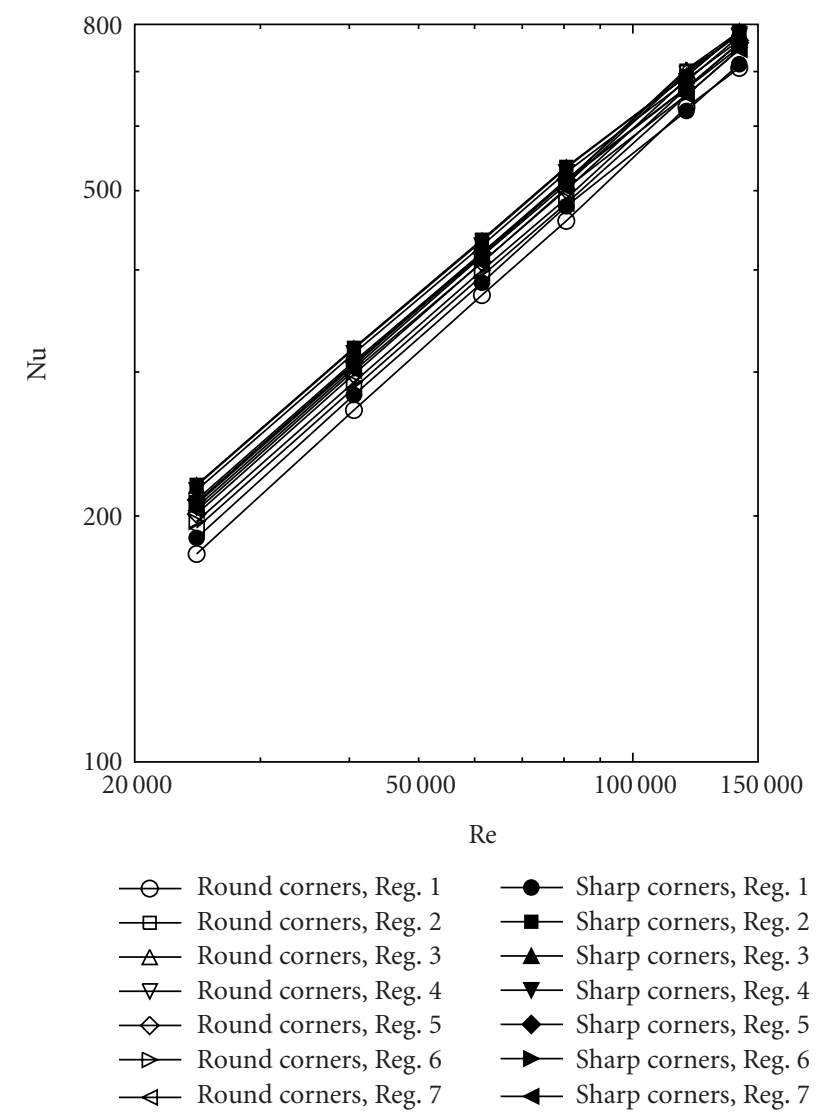

Figure 8: Comparison between the numerical results for sharp- and round-corner ribs with $20 \%$ blockage ratio $\left(e / D_{h}=0.2, P / e=10\right)$.

number region. Liquid crystal displays of isochrome confirm the same behavior. These figures indicate that, unlike the $90^{\circ}$ ribs, angled ribs create a remarkable spanwise variation in the heat transfer coefficient. As mentioned earlier, spanwise, counterrotating, double-cell secondary flows created by angling of ribs are responsible for this variation. It can also be seen that on the top wall, close to the ribs on both ends, there are regions of low Nusselt numbers (high temperatures). Again, liquid crystal displays showed the same behavior. This phenomenon can be best explained by looking at Figure 12 which shows the velocity vectors close to the ribs and channel surfaces. All high Nusselt number regions mentioned above correspond to high-velocity regions in this figure. These high-velocity regions, however, correspond to where rotating cells, shown in Figure 6, bring the cooler core air in contact with the channel surface. The low Nusselt number regions, on the other hand, see exactly the opposite action, that is, the rotating cell draws the air towards the channel center thus slowing down the axial air around those regions.

\section{CONCLUSIONS}

Comparisons between the test and numerically evaluated results showed good agreements between the two for most 

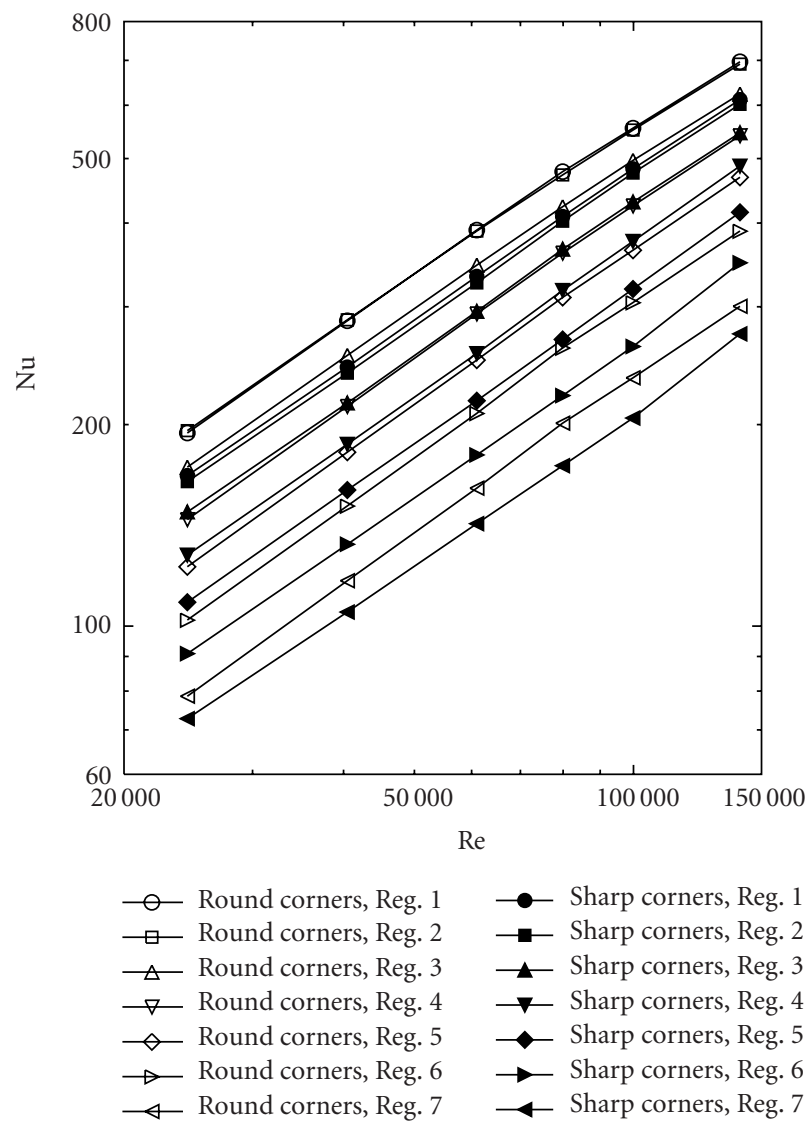

FIGURE 9: Comparison between the numerical results for sharp- and round-corner ribs with $25 \%$ blockage ratio $\left(e / D_{h}=0.25, P / e=10\right)$.

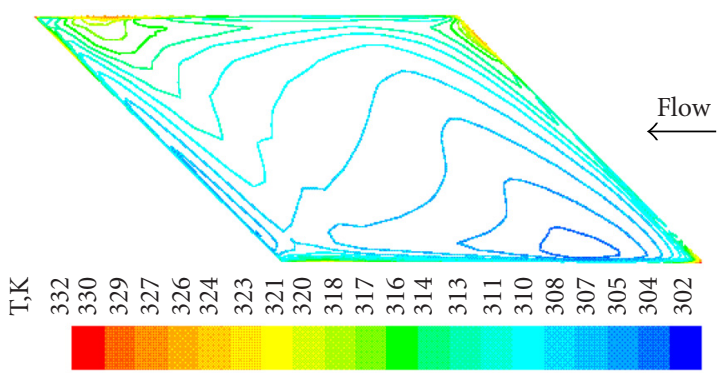

FIgURE 10: Representative isotherms on the surface area between a pair of ribs.

cases. Therefore, CFD could be considered as a viable tool for the prediction of heat transfer coefficients in rib-roughened test sections, especially during the parametric studies in early design process. It was also concluded that, unlike the ribs that are mounted perpendicular to the flow direction, $45^{\circ}$ angled ribs with high blockage ratios $(>0.2)$ do not exhibit a good thermal performance, that is, as rib blockage increases, the heat transfer coefficient decreases and, roundcorner high blockage ribs are superior to those with sharp corners.

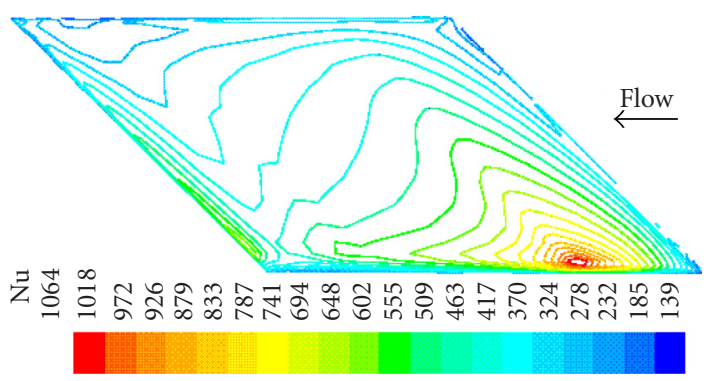

FIGURE 11: Representative iso-Nu contours on the surface area between a pair of ribs.

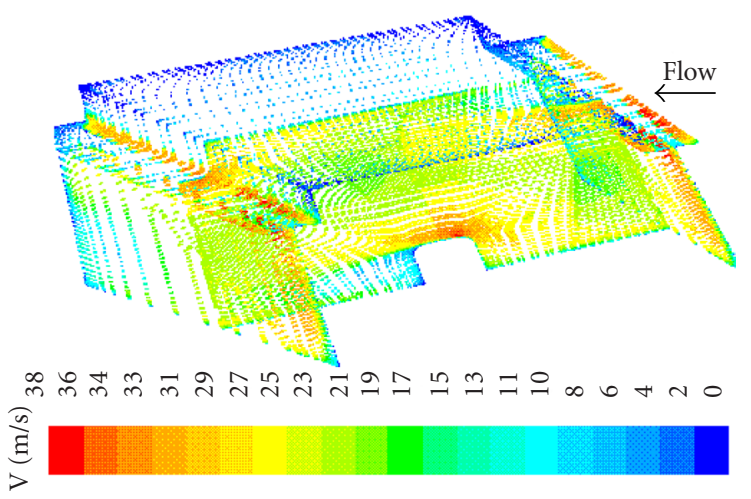

FIGURE 12: Representative velocity vectors around the ribs and on the channel center plane.

\section{REFERENCES}

[1] F. Burggraf, "Experimental heat transfer and pressure drop with two-dimensional turbulence promoter applied to two opposite walls of a square tube," in ASME Augmentation of Convective Heat and Mass Transfer, A. E. Bergles and R. L. Webb, Eds., pp. 70-79, 1970.

[2] P. R. Chandra and G. C. Han, "Pressure drop and mass transfer in two-pass ribbed channels," AIAA J. Thermophysics, vol. 3, no. 3, pp. 315319, 1989.

[3] P. R. Chandra, "Effect of rib angle on local heat/mass transfer distribution in a two pass rib-roughened channel," ASME Paper \#87-GT-94, 1987.

[4] G. C. Han, L. R. Glicksman, and W. M. Rohsenow, "An investigation of heat transfer and friction for rib-roughened surfaces," Int. J. Heat Mass Transfer, vol. 21, pp. 1143-1156, 1978.

[5] J. C. Han, "Heat transfer and friction in channels with two opposite rib-roughened walls," J. Heat Transfer, vol. 106, no. 4, pp. 774-781, 1984.

[6] J. C. Han, J. S. Park, and C. K. Lei, "Heat transfer enhancement in channels with turbulence promoters," J. Engr. for Gas Turbines Power, vol. 107, pp. 628-635, 1985.

[7] D. E. Metzger, C. S. Fan, and G. W. Pennington, "Heat transfer and flow friction characteristics of very rough transverse ribbed surfaces with and without pin fins," in Proc. ASMEJSME Thermal Engineering Joint Conference, vol. 1, pp. 429436, Honolulu, Hawaii, USA, 1983.

[8] M. E. Taslim, T. Li, and D. M. Kercher, "Experimental heat transfer and friction in channels roughened with angled, Vshape and discrete ribs on two opposite walls," J. Turbomachinery, vol. 118, pp. 20-28, 1996. 
[9] M. E. Taslim, L. A. Bondi, and D. M. Kercher, "An experimental investigation of heat transfer in an orthogonally rotating channel roughened 45 degree criss-cross ribs on two opposite walls," J. Turbomachinery, vol. 113, pp. 346-353, 1991.

[10] R. L. Webb, E. R. G. Eckert, and R. J. Goldstein, "Heat transfer and friction in tubes with repeated-rib roughness," Int. J. Heat Mass Transfer, vol. 14, pp. 601-617, 1971.

[11] S. C. Lau, R. D. McMillin, and J. C. Han, "Heat transfer characteristics of turbulent flow in a square channel with angled discrete ribs," J. Turbomachinery, vol. 111, no. 2, pp. 117-123, 1990.

[12] G. C. Han, Y. M. Zhang, and C. P. Lee, "Augmented heat transfer in square channels with parallel, crossed, and V-shaped angled ribs," J. Heat Transfer, vol. 113, pp. 590-596, 1991.

[13] D. E. Metzger, M. K. Chyu, and R. S. Bunker, "The contribution of on-rib heat transfer coefficients to total heat transfer from rib-roughened surfaces," in Transport Phenomena in Rotating Machinery, J. H. Kim, Ed., Hemisphere Publishing, Washington, DC, USA, 1988.

[14] G. J. Korotky and M. E. Taslim, "Rib heat transfer coefficient measurements in a rib-roughened square passage," J. Turbomachinery, vol. 120, no. 2, pp. 376-385, 1988.

[15] M. E. Taslim and G. J. Korotky, "Low-aspect-ratio rib heat transfer coefficient measurements in a square channel," J. Turbomachinery, vol. 120, pp. 831-838, 1998.

[16] M. E. Taslim and A. Lengkong, " $45^{\circ}$ staggered rib heat transfer coefficient measurements in a square channel," J. Turbomachinery, vol. 120, no. 3, pp. 571-580, 1998.

[17] M. E. Taslim and A. Lengkong, " $45^{\circ}$ round-corner rib heat transfer coefficient measurements in a square channel," J. Turbomachinery, vol. 121, pp. 1-9, 1999.

[18] S. J. Kline and F. A. McClintock, "Describing uncertainty in single-sample experiments," Mechanical Engineering, vol. 75, pp. 3-8, 1953.

[19] C. S. Fan, W. J. Yang, and N. Zhang, "Local heat transfer in a rotating serpentine passage with rib-roughed surfaces," Int. J. Heat and Mass Transfer, vol. 37, no. 2, pp. 1143-1156, 1990.

[20] D. E. Metzger, C. S. Fan, and Y. Yu, "Effects of rib angle and orientation on local heat transfer in square channels with angled roughness ribs," in Compact Heat Exchangers: A Festschrift for A.L. London, pp. 151-167, Hemisphere Publishing, Washington, DC, USA, 1990. 

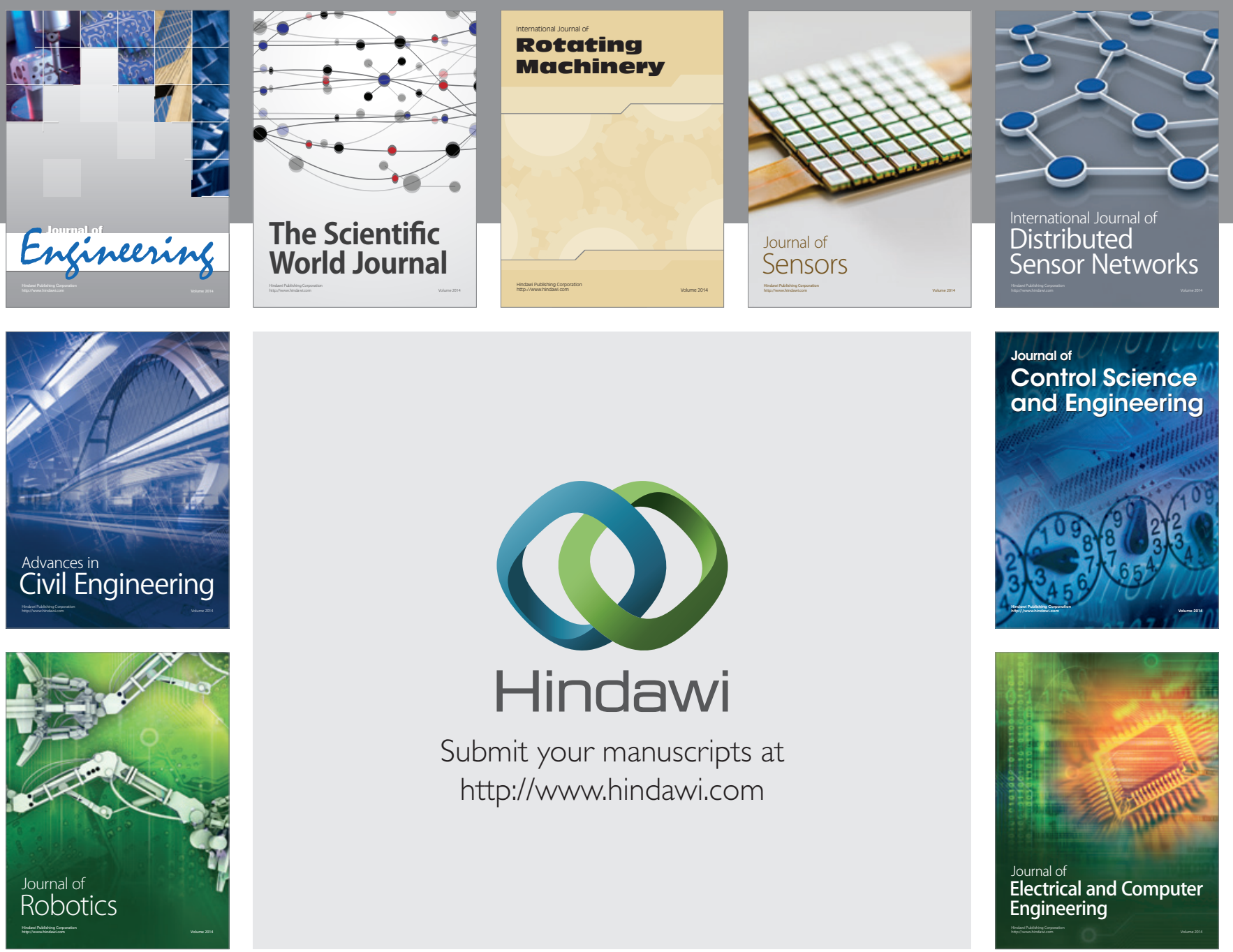

Submit your manuscripts at

http://www.hindawi.com
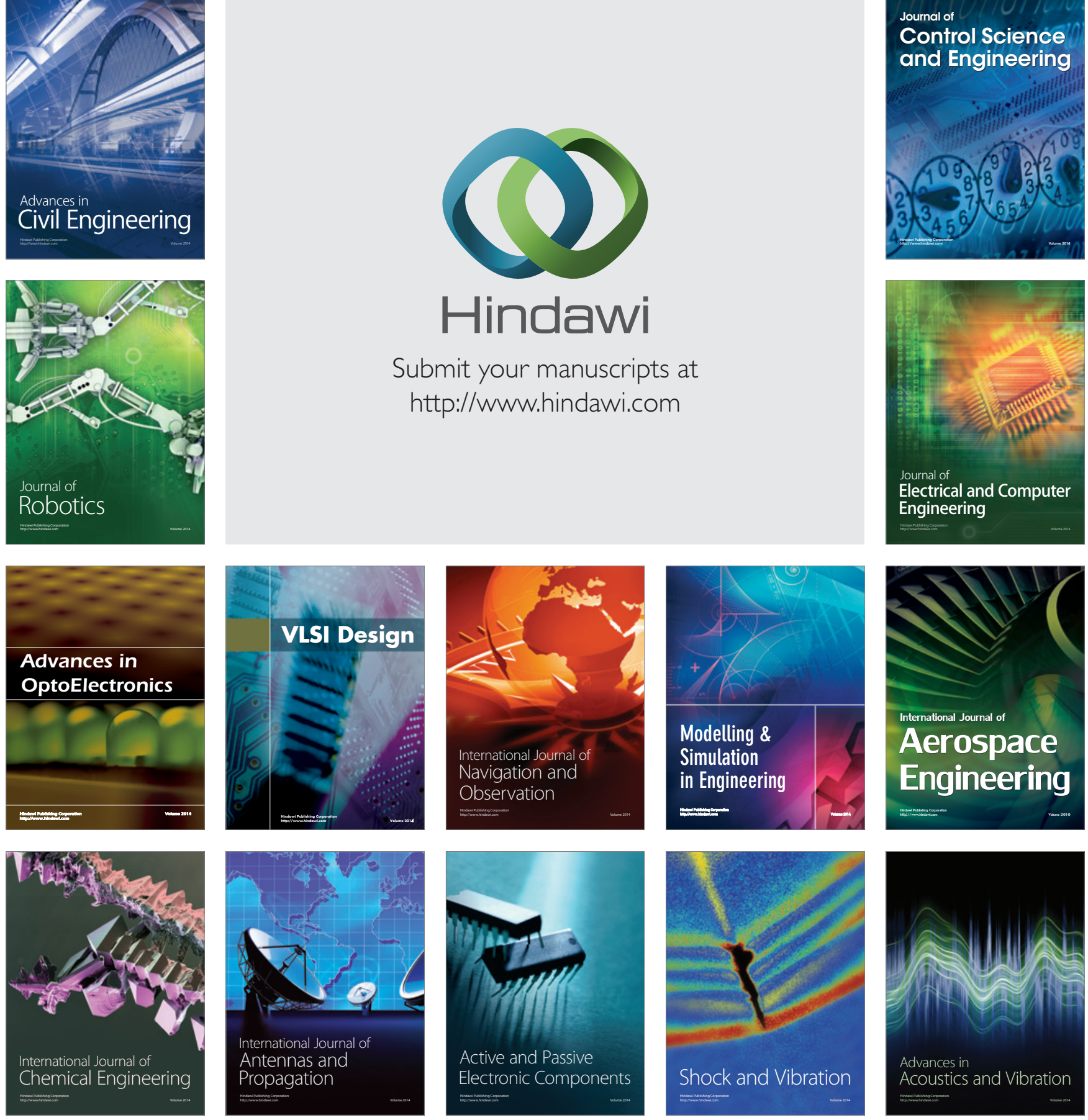